\title{
Low-cost PMMA-based microfluidics for the visualization of enhanced oil recovery
}

\author{
Yiqiang Fan ${ }^{1, *}$, Kexin $\mathrm{Gao}^{1}$, Jie $\mathrm{Chen}^{2}$, Wengang $\mathrm{Li}^{3}$, and Yajun Zhang ${ }^{1}$ \\ ${ }^{1}$ School of Mechanical and Electrical Engineering, Beijing University of Chemical Technology, Beijing 100029, China \\ 2 BGP Geological Research Center, BGP CNPC, Zhuozhou 072750, China \\ ${ }^{3}$ EXPEC Advanced Research Center, Saudi Aramco, Dhahran 31311, Saudi Arabia
}

Received: 16 January 2018 / Accepted: 18 June 2018

\begin{abstract}
About one-third of the crude oil is trapped inside the pores of the carbonate and sandstone after the primary and secondary oil recovery, various methods have been used for the flooding of the trapped crude oil. Due to the opaque nature of the sandstone and shale, the visualization of the fluid flow inside the porous structure conventionally involved the use of very sophisticated equipment like X-ray computed microtomography. In this approach, a low-cost method for the mimic of porous structure for the enhanced oil recovery is proposed using the polymethyl methacrylate (PMMA)-based microfluidic devices with the laser ablated microstructures, where the microstructure is the replica of a real rock fracture. Since the PMMA is optically clear in the visible range, the detailed fluid flow inside the porous structure could be obtained for a better understanding of the liquid front propagation and rheology in the pore-scale. The effect of water flooding is also tested with the proposed microfluidic devices under various flooding rates for the demonstration of oil recovery enhancement with the proposed technology.
\end{abstract}

\section{Introduction}

During the process of crude oil production, after the geological survey and drilling of wells, the recovery of oil is usually classified as three stages: the primary, secondary and tertiary. In the primary stage, the oil could be driven by the reservoir pressure or use the artificial lifting to bring the oil to the surface, less than $30 \%$ of the total reserves are obtained in this stage. In the secondary stage, the fluid (i.e. water) or gas is injected for the forced displacement of oil, another 10-20\% of the oil is recovered after this stage. In the tertiary stage, various thermal, chemical, and solvent methods are used for the further pushing of the oil trapped in the porous media in the rock to the production well. The tertiary stage is usually called the Enhanced Oil Recovery (EOR) process, after which a further $5-35 \%$ of the total oil reserve is expected to be recovered.

For the chemical or solvent flooding in EOR process, the displacing fluid is applied to displace the oil trapped inside the porous media. The main working principle of chemical or solvent flooding is to lower the mobility ratio for a better displacing of trapped oil and increase the capillary number for more efficiently displacing with the fluid flood. The current EOR methods include flooding with surfactants [1, 2], polymers $[3,4]$, foams $[5,6]$, microorganisms $[7,8]$ and even

\footnotetext{
* Corresponding author: fanyq@mail. buct.edu.cn
}

with supercritical gas such as $\mathrm{N}_{2}[9]$ and $\mathrm{CO}_{2}[10,11]$. However, the study of the surfactant or chemical flooding for the EOR is based on the past experience and the flooding result, the porous rock with trapped oil is still a "black box" during the flooding process. Although some attempts have been made for the visualization of the flow inside the porous media using synchrotron-based X-ray computed microtomography [12, 13] or confocal microscope [14], besides the danger of radiation, these methods all require expensive and highly sophisticated instruments.

The concept of microfluidics can be traced back to the early 90's [15] aiming at handling the fluid in the micro or nanoscale, which is in same range of the porous media in the rock. Currently, microfluidic has been widely used in the chemical [16] and biological fields [17], the fabrication and characterization technologies of the microfluidic chips have been studied extensively. As an aspect of microfluidic applications in energy frontier [18], the microfluidics could be used for the mimic of porous media in shale or sandstone. Besides reconstruction of porous media, microfluidic devices provide a more precise control and observation of fluid flow in micro or nano scale. The accumulated studies in microfluidics could provide sufficient technologies for the actuate replica of porous microstructures from sandstone or shales onto microfluidic chips with various polymer [19, 20], glass [21, 22], or silicon [23] materials with controlled surface properties $[24,25]$. 
For the observation and study of multiphase flow in pore-scale, micromodels have been widely used for decades, the emerging trend of using microfluidic-based micromodels have found more and more applications in the EOR process simulation and study. Various mimic EOR processes have been conducted in the polymer, glass or silicon-based microfluidic devices, using foams [26,27], chemical [28] and polymer [29] flooding; the wettability and hydrodynamic cavitation generation study of the multiphase flow inside the microfluidic devices has also been conducted [30,31].

Various microfabrication methods have been used in the fabrication of microfluidic devices for EOR process study, including optical lithography, chemical etching, plasma etching and stereo lithography. These fabrication methods usually involved a complicated fabrication procedures with highly sophisticated instruments, which formed a technical barrier for the researchers in energy fields to be benefit from microfluidics technology. In this research, the $\mathrm{CO}_{2}$ laser is being used for a low-cost and rapid prototyping of microfluidic devices for EOR process, comparing with other microfabrication methods, the $\mathrm{CO}_{2}$ laser ablation is a one-step fabrication procedure, the polymer material on the laser focused point is melting down and evaporated, and the microstructure is formed directly with laser scan. With the wide applications of $\mathrm{CO}_{2}$ laser instrument in industry, the cost of $\mathrm{CO}_{2}$ laser instruments is significantly lower than the sophisticated microfabrication instruments used in optical lithography or etching process.

Polymethyl methacrylate (PMMA) is a widely used thermal plastic material in daily life and frequently being used as an alternative to glass, PMMA is optically clear in visual range and low-cost, the PMMA is relatively easy for processing and handling. Various microfabrication methods for the PMMA-based microfluidics have been reported using photolithography [32], hot-embossing [33], injection molding [34] and laser ablation [35]. However, using PMMA-based microfluidic device in EOR process study is rarely reported in the previous study.

In this study, in order to lower the barrier of visualization and cost in EOR process, the PMMA was chosen as the bulk material for the microfluidic devices with laser ablated microstructures to mimic the porous media inside the sand-

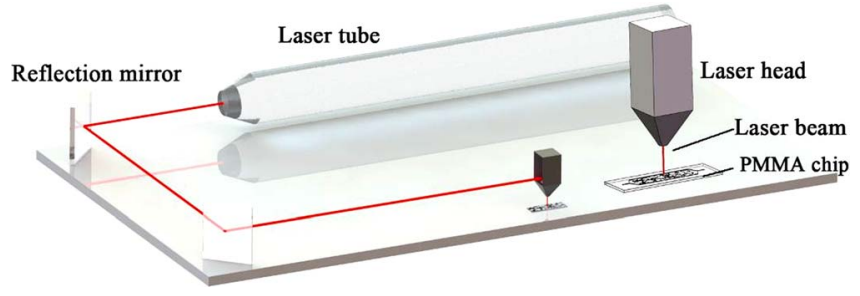

Fig. 1. Schematic of the laser ablation system.

stone. PMMA is optically clear in the visual range, the flooding process of the crude oil trapped inside the porous media can be observed directly. The fabrication and material cost for each microfluidic chip using the proposed method is lower than $\$ 5$, which may significantly lowered the cost to achieve the visualization of EOR process. For the demonstration of the proposed technique, the PMMA-based microfluidic devices were fabricated, water flooding with various rates were performed with the fabricated microfluidic chips and the results were carefully analyzed.

\section{Fabrication}

\subsection{Instruments, materials, and software}

The $\mathrm{CO}_{2}$ laser was used for the direct laser ablation (engrave) of microstructures on the surface of PMMA, the $\mathrm{CO}_{2}$ laser system (HTE-1206) is sourced from Hantone CNC Equipment, China, with the wavelength of $10.6 \mu \mathrm{m}$, the output power could be adjusted from 0 to $80 \mathrm{~W}$, and laser scan speed could be adjusted from 0 to $400 \mathrm{~mm} \mathrm{~s}^{-1}$ (shown in Fig. 1). The laser head is controlled with two stepping motors which can move in $X$ and $Y$ directions, the scan route of the laser head was planned based on the true image of the sandstone with software. The syringe pump (11 Elite syringe pump) used in this research is from Harvard Apparatus, USA. The hotplate (Cimarec+) is from Thermo Fisher Scientific, USA. The camera used for taking

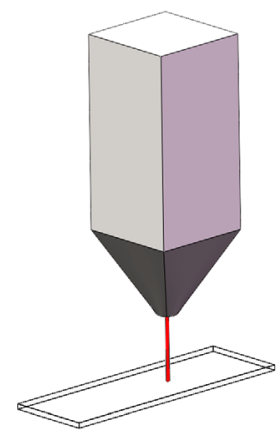

Laser ablation

(a)

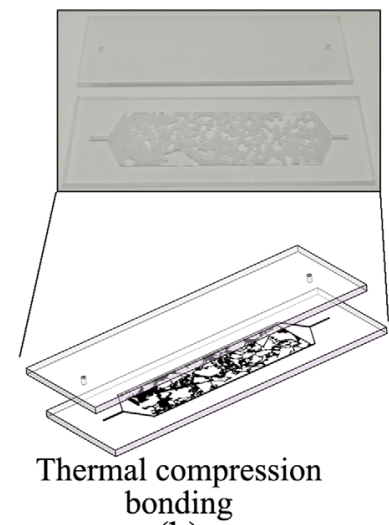

(b)

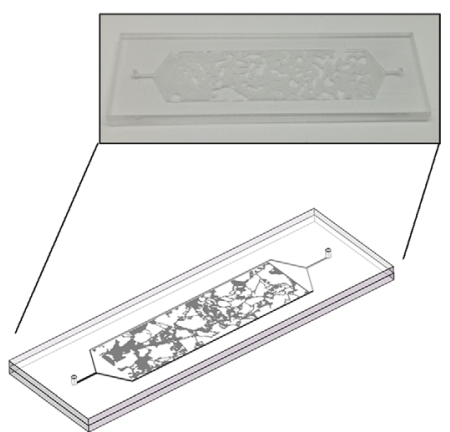

Fabricated chip

(c)

Fig. 2. Schematic of the fabrication process for PMMA-based microfluidic chips. 


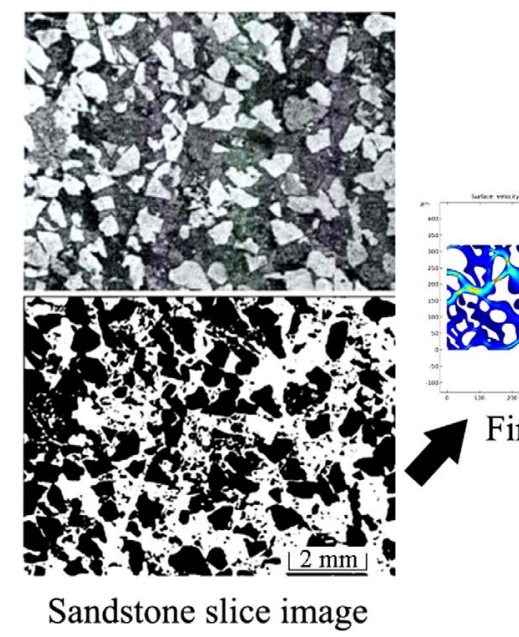

(a)

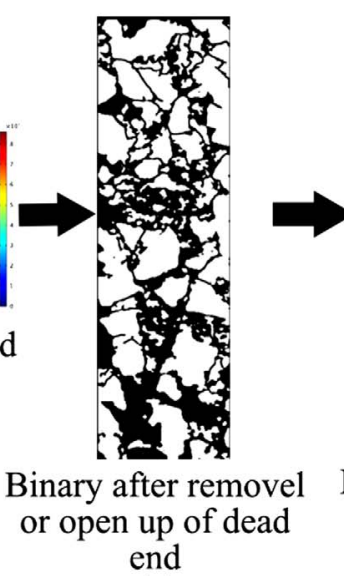

(c)

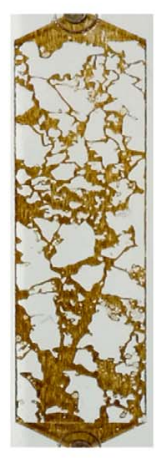

Fabricated chip, after crude oil fulfillment

(d)

Fig. 3. The replica of the true sandstone image on PMMA substrate. (a) The image of the sandstone slide and after converted to a grayscale image. (b) Numerical simulation to find the dead end. (c) Convert image to binary and remove or open up the dead end. (d) The image after crude oil fulfillment.

images of the flooding is Canon 500D, with EF-S 18-55 mm lens. The heat press (Model 4386) used for the chip bonding is from Carver, Inc. USA.

Crude oil and sandstone slice image used in this study were origin from Sulige field, Inner Mongolia, China. The casted PMMA sheet (1.3 mm thick) is sourced from Goodfellow Cambridge Limited, United Kingdom. MATLAB (The MathWorks, Inc.) was used for the image processing and analysis, the automated image processing program was developed for the real-time continues analysis of the crude oil flooding in the microfluidic devices.

\subsection{Chip fabrication and bonding}

The fabrication process of the PMMA-based microfluidic device is shown in Figure 2. The $\mathrm{CO}_{2}$ laser was used for the direct ablation of microstructures on the surface of PMMA substrate (Fig. 2a), the power was set at $28 \mathrm{~W}$ while the scan speed was set at $30 \mathrm{~mm} \mathrm{~s}^{-1}$. The pattern of laser ablated microstructures are sourced from a true slice image from sandstone, the original image was converted into a binary pattern and used for laser engraving. The external dimension of the PMMA substrate is $25.4 \mathrm{~mm}$ by $76.2 \mathrm{~mm}$.

After laser ablation, the PMMA substrate was cleaned with DI water and ethanol, then bonded with another layer of PMMA (cover plate) with the same dimension (Fig. 2b) to seal the microstructures. The cover plate has two laser fabricated through holes for inlet and outlet ports. The bonding was achieved using thermal compression bonding method, the temperature was set at $95{ }^{\circ} \mathrm{C}$ with a pressure of $0.5 \mathrm{MPa}$ for $15 \mathrm{~min}$. During the thermal compression process, the molecule chain of polymers will loose and entangle with each other at the contacted area and form a bonding after cooling, maximum bonding strength was achieved after natural cooling (Fig. 2c). The pipes (outer diameter $1.19 \mathrm{~mm}$, Silastic Laboratory Tubing, Dow Corning
Corporation, USA) for inlet and outlet ports were then connected to the inlet and outlet ports to finish the fabrication process of the microfluidic chip for EOR research.

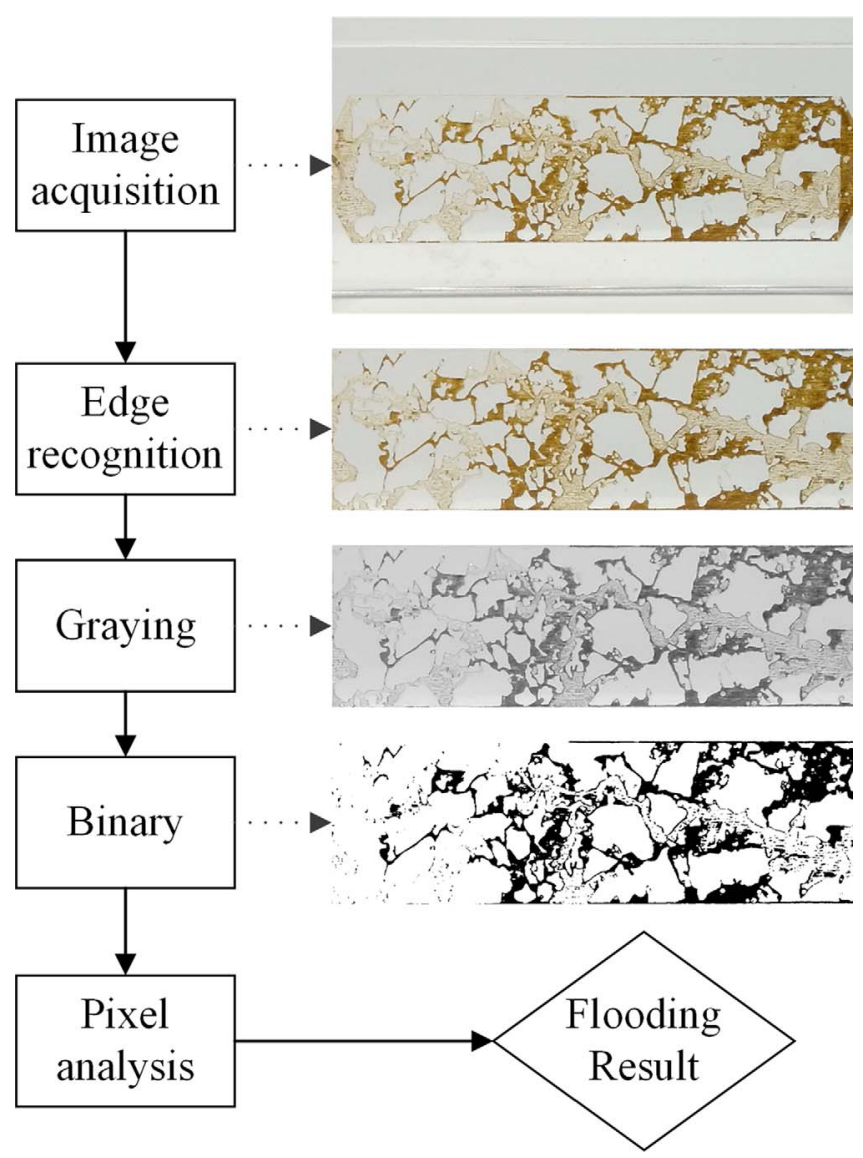

Fig. 4. Flow chart for the fully automated image processing during water flooding. 

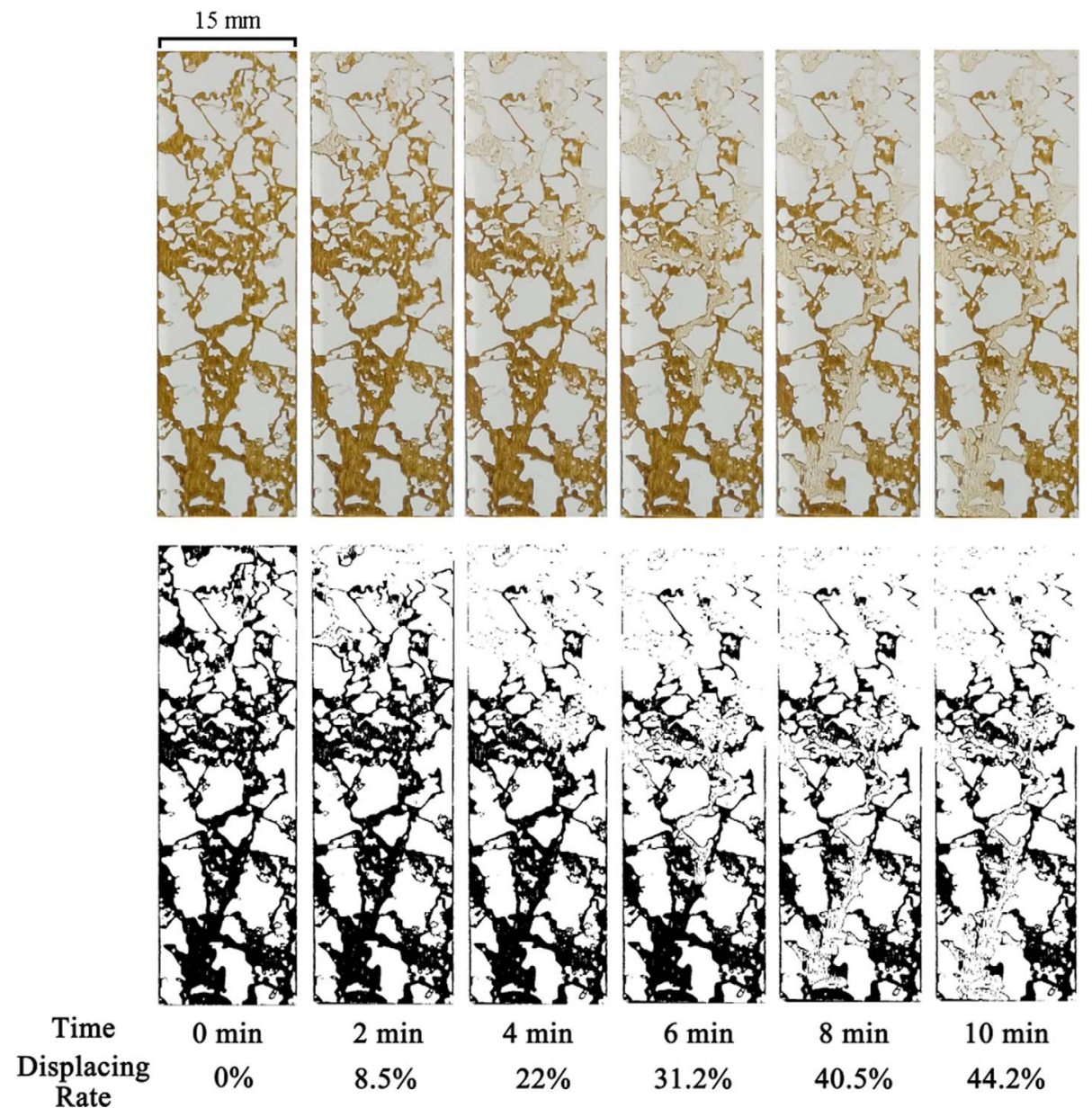

Fig. 5. Images of the microfluidic chip and corresponding binary images during the flooding process.

\section{Result and discussion}

Before sending to laser ablation, the true image of the sandstone slice needs serval amendments. The processes are shown in Figure 3, the image obtained under themicroscope will first be converted to a grayscale image (Fig. 3a), then further converted to a binary image with only black and white region. A numerical simulation was conducted to identify the "dead end" from the binary image (Fig. 3b, with COMSOL Multiphysics, COMSOL Inc.), these "dead end" could be chosen by users to keep the originally state or to manually open up the "dead end". Since the transport in dead-end pore is not possible in the conventional pressure-driven flow [36], the water flooding process in EOR cannot reach these dead-end pores, in order to enhance the fluid flow inside the pore structure, the dead-end pore is manually open up with the image processing in this study. The black region will later be etched with laser ablation in the fabrication process (Fig. 3c). The fabricated microfluidic chip after crude oil fulfillment is shown in Figure 3d.

After microfluidic chip fabrication, the flooding test was performed for the demonstration of the proposed technology using the microfluidic chip as the visualization tool for the study of EOR process. The cured oil was injected into the microfluidic chip with a speed of $1 \mu \mathrm{L} / \mathrm{min}$ to fulfill the microstructures inside the chip. After $10 \mathrm{~min}$ for stabilization, the ion water $\left(\mathrm{NaCl}, 5000 \mathrm{ppm}\right.$ at $\left.45^{\circ} \mathrm{C}\right)$ was used for the flooding of crude oil inside the chip, with the intention to mimic the EOR process in the sandstone. The water flooding was carefully monitored with camera and the images could be automate analyzed for the displacing rate with our program running in MATLAB.

The detailed flow chart of the fully automated image processing is shown in Figure 4, the images taken with DSLR camera were transferred to the program, and the edges of the microstructures were identified. After that, the image was converted into a grayscale image and then further converted to a binary image. Finally, the program counted the black pixels and compared the amount of black pixels in the original binary image after crude oil fulfillment to obtain the displacing rate. Simply put, the image processing process is calculating when and how many black pixels is turning to white during the water flooding. For the pixel counting percentage variation measurement, five images were taken on the same spot with a time interval of $0.2 \mathrm{~s}$, the pixel counting result shows percentage variation measurement is around $4.5 \%$. 


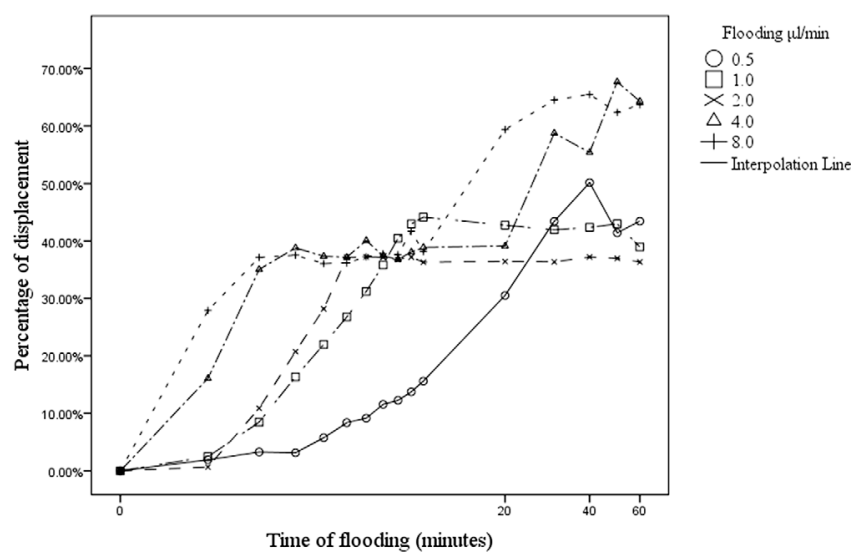

Fig. 6. Displacing rate of crude oil with water flooding under various flooding speeds.

A sequence of images were provided in Figure 5 during the water flooding process. The images were taken every 2 min with a water flooding speed of $2 \mu \mathrm{L} / \mathrm{min}$ with the temperature of $45^{\circ} \mathrm{C}$. The corresponding binary images and the calculated displacing rates are also shown in Figure 5. Result indicates that about $44.2 \%$ of the crude oil was being pushed out (displaced) after 10 minutes' water flooding. The detailed information of the water flooding result using the PMMA-based microfluidic chips is plot in Figures 6 and 7, the water flooding is conducted with flooding speed of $0.5,1,2,4$, and $8 \mu \mathrm{L} / \mathrm{min}$, the displacing rate is

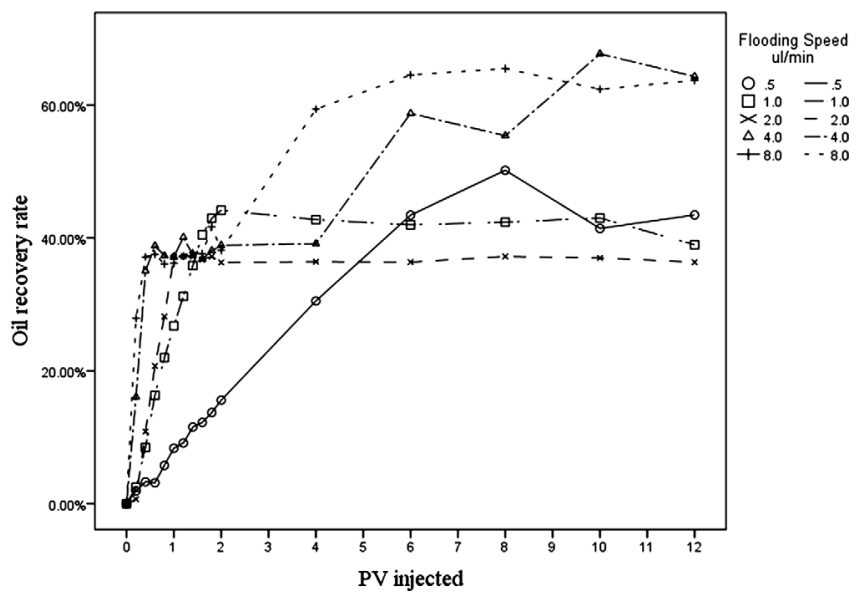

Fig. 7. Oil recovering rate versus PV injected under various flooding rates.

monitored in real-time continuously for $60 \mathrm{~min}$. Several conclusions can be made based on this line chart. Firstly, the speed of displacing is rapid at the first 10-15 min, then slowing down after $20 \mathrm{~min}$ and finally reached a saturation after about $60 \mathrm{~min}$. Secondly, the flooding speed has a positive correlation of the displacing rate, which indicates the high water flooding speed pushed out more crude oil at the same period. Thirdly, the maximum displacing rate can be reached is around $64 \%$, still left a lot of room for further improvement in the future study, the employment of

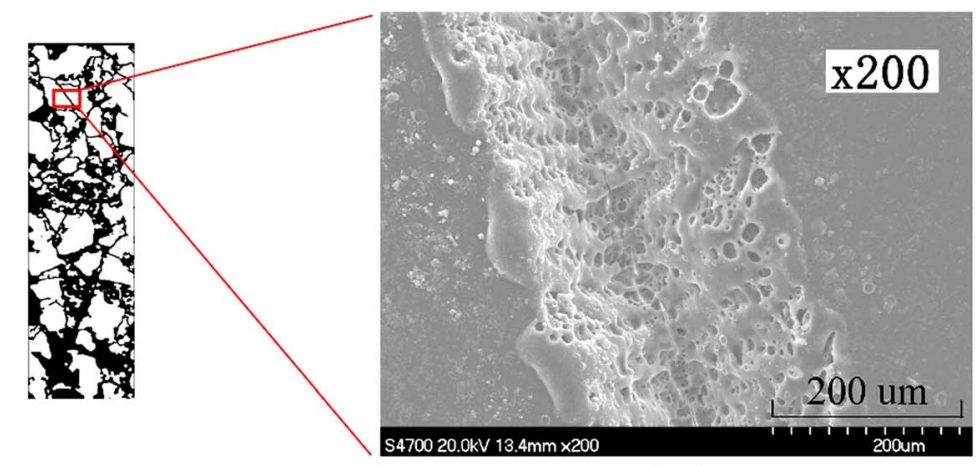

(a)

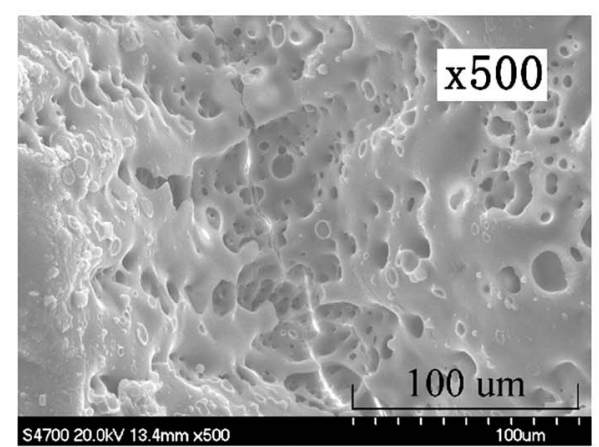

(b)

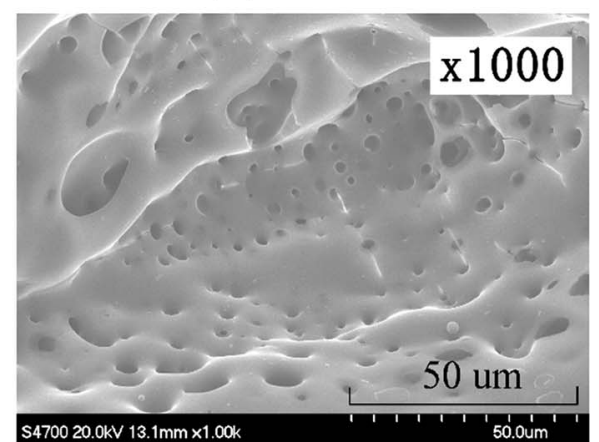

(c)

Fig. 8. SEM images of the laser ablated microstructures on PMMA substrate. 
surfactant or foam might be the study directions. The above experimental procedure is repeated for three times, result in a percentage variation around $6.2 \%$, which the variation is sourced from the flooding pressure fluctuate, and some random error from the experimental process and image processing.

The SEM images of the laser ablated microstructures are shown in Figure 8, which were magnified with 200, 500 and 1000 times (taken by S-4700, Hitachi High-Technologies Corporation, Japan). Figure 8a shows a channellike structure on the surface of PMMA, and Figures $8 \mathrm{~b}$ and $8 \mathrm{c}$ are the enlarged images on the same spot. The porous structure on the surface of laser ablated area is caused by the rapid phase change of polymer material since $\mathrm{CO}_{2}$ laser ablation is a purely thermal process, the polymer material will rapidly soften, melting down, decompose and vaporize, resulting in a porous structure on the laser ablated area. With the laser power of $28 \mathrm{~W}$ and scan speed of $30 \mathrm{~mm} \mathrm{~s}^{-1}$, the mean depth of the laser ablated microstructure on the surface of PMMA is around $250 \mu \mathrm{m}$, with a fluctuation around $30 \mu \mathrm{m}$, which is caused by the nonuniform moving speed of focused laser spot on PMMA sourced from the mechanical constrains of laser ablation instrument. The porous structure on the surface of laser ablated area is considered to be a vivid imitation of the porous structure in sandstone in this study.

\section{Conclusion}

The visualization of the water flooding process in the PMMA-based microfluidic devices is achieved in this study, which could mimic the porous sandstone. The microfluidic devices were fabricated using laser ablation based on the true slice image of sandstone and thermally bonded to seal the fabricated microstructure. The flooding process was carefully analyzed using a custom-made automated image processing program which continuously monitored the trapped crude oil displacement. This study indicates that the use of laser-ablated PMMA microfluidic devices could effectively mimic the microstructures in the sandstone, which is helpful for a better understanding of the fluid prorogation inside the sandstone. The PMMA-based microfluidic devices provided a simple and low-cost visualization tool for the study of EOR process.

For future study of polymer microfluidics in EOR, various surface treatments should be carefully studied to provide a more flexible choice of surface wettability based on different sandstone conditions. Surfactant and foam flooding should also be studied using polymer microfluidics for the mimic of EOR process. Besides polymer materials, other materials like ceramic or silicon should also be considered to be used in the fabrication of microfluidic devices with a transparent material for the sealing of microstructure, since the physical and chemical property of ceramic and silicon are much more similar to the sandstone or shale.

Acknowledgments. This work was supported by the Fundamental Research Funds for the Central Universities (buctrc201609).

\section{References}

1 Lu J., Liyanage P.J., Solairaj S., Adkins S., Arachchilage G.P., Kim D.H., Britton C., Weerasooriya U., Pope G.A. (2014) New surfactant developments for chemical enhanced oil recovery, J. Petrol. Sci. Eng. 120, 94-101.

2 Hirasaki G., Miller C.A., Puerto M. (2011) Recent advances in surfactant EOR, SPE J. 16, 889-907.

3 Malik I.A., Al-Mubaiyedh U.A., Sultan A.S., Kamal M.S., Hussein I.A. (2016) Rheological and thermal properties of novel surfactant-polymer systems for EOR applications, Can. J. Chem. Eng. 94, 1693-1699.

4 Lai N., Wu T., Ye Z., Zhang Y., Zhou N., Zeng F. (2016) Hybrid hyperbranched polymer based on modified $\mathrm{Nano}_{-} \mathrm{SiO}_{2}$ for enhanced oil recovery, Chem. Lett. 45, 1189-1191.

5 Nguyen P., Fadaei H., Sinton D. (2014) Pore-scale assessment of nanoparticle-stabilized $\mathrm{CO}_{2}$ foam for enhanced oil recovery, Energy Fuels 28, 6221-6227.

6 Rossen W., Ocampo A., Restrepo A., Cifuentes H., Marin J. (2017) Long-time diversion in surfactant-alternating-gas foam enhanced oil recovery from a field test, SPE Reserv. Evalu. Eng. 20, 1, 1-7.

7 Brown L.R. (Jun 2010) Microbial enhanced oil recovery (MEOR), Curr. Opin. Microbiol. 13, 316-320.

8 Patel J., Borgohain S., Kumar M., Rangarajan V., Somasundaran P., Sen R. (2015) Recent developments in microbial enhanced oil recovery, Renew. Sust. Energ. Rev. 52, 1539 1558.

9 Meng X., Zhang Z.Z., Wang S., Shen A. (2013) Biodegradation of paraffin crude oil by an Isolated Pseudomonas aeruginosa $\mathrm{N}_{2}$ for enhanced oil recovery, Adv. Mater. Res. 616-618, 924-930.

10 Li L., Khorsandi S., Johns R.T., Dilmore R.M. (2015) $\mathrm{CO}_{2}$ enhanced oil recovery and storage using a gravity-enhanced process, Int. J. Greenhouse Gas Control 42, 502-515.

11 Du B., Cheng L. (2014) Experimental study of enhanced oil recovery with $\mathrm{CO}_{2}$ slug $+\mathrm{N}_{2}$ flood in low permeability reservoir, Geosyst. Eng. 17, 279-286.

12 Berg S., Armstrong R.T., Georgiadis A., Ott H., Schwing A., Neiteler R., Brussee N., Makurat A., Rucker M., Leu L., Wolf, M. (2015) Onset of oil mobilization and nonwettingphase cluster-size distribution, Petrophysics 56, 15-22.

13 Landry C.J., Karpyn Z.T., Ayala O. (2014) Pore-scale lattice Boltzmann Modeling and 4D X-ray computed microtomography imaging of fracture-matrix fluid transfer, Transp. Porous Media 103, 449-468.

14 Li Y., Li J., Ding S., Sun X. (2014) Characterization of remaining oil after polymer flooding by laser scanning confocal fluorescence microscopy, J. Dispers. Sci. Technol. 35, 898-906.

15 Gravesen P., Branebjerg J., Jensen O.S. (1993) Microfluidics - a review, J. Micromech. Microeng. 3, 168.

16 Liu Y., Jiang X. (2017) Why microfluidics? Merits and trends in chemical synthesis, Lab Chip 17, 3960-3978.

17 Mahesh K., Vaidya S. (2017) Microfluidics: A boon for biological research, Current Science 112, 2021.

18 Sinton D. (2014) Energy: the microfluidic frontier, Lab Chip 14, 3127-3134.

19 Begolo S., Colas G., Viovy J.L., Malaquin L. (2011) New family of fluorinated polymer chips for droplet and organic solvent microfluidics, Lab Chip 11, 508.

20 Becker H., Locascio L.E. (2002) Polymer microfluidic devices, Talanta 56, 267-287. 
21 Othman R., Vladisavljević G.T., Nagy Z.K. (2015) Preparation of biodegradable polymeric nanoparticles for pharmaceutical applications using glass capillary microfluidics, Chem. Eng. Sci. 137, 119-130.

22 Kim S.M., Burns M.A., Hasselbrink E.F. (2006) Electrokinetic protein preconcentration using a simple glass/poly(dimethylsiloxane) microfluidic chip, Anal. Chem. 78, 4779-4785.

23 Leïchlé T., Bourrier D. (2015) Integration of lateral porous silicon membranes into planar microfluidics, Lab Chip 15, $833-838$.

24 Vourdas N., Tserepi A., Boudouvis A.G., Gogolides E. (2008) Plasma processing for polymeric microfluidics fabrication and surface modification: Effect of super-hydrophobic walls on electroosmotic flow, Microelectron. Eng. 85, 1124-1127.

25 Tu Q., Wang J.C., Zhang Y., Liu R., Liu W., Ren L., Shen S., $\mathrm{Xu}$ J., Zhao L., Wang J. (2012) Surface modification of poly(dimethylsiloxane) and its applications in microfluidicsbased biological analysis, Rev. Anal. Chem. 31, 177-192.

26 Quennouz N., Ryba M., Argillier J.F., Herzhaft B., Peysson Y., Pannacci N. (2014) Microfluidic study of foams flow for Enhanced Oil Recovery (EOR), Oil Gas Sci. Technol. - Rev. IFP Energies nouvelles 69, 457-466.

27 Vial C., Narchi I. (2013) Development of a Model Foamy Viscous Fluid, Oil Gas Sci. Technol. - Rev. IFP Energies nouvelles 69, 481-497.

28 Marciales A., Babadagli T. (2016) Pore scale visual investigations on solvent retrieval during oil recovery at elevated temperatures: A micromodel study, Chem. Eng. Res. Des. 106, 59-73.
29 Lacey M., Hollis C., Oostrom M., Shokri N. (2017) Effects of pore and grain size on water and polymer flooding in micromodels, Energy Fuels 31, 9026-9034.

30 Zhao B., MacMinn C.W., Juanes R. (2016) Wettability control on multiphase flow in patterned microfluidics, Proc. Natl. Acad. Sci. USA 113, 10251-10256.

31 Ayela F., Cherief W., Colombet D., Ledoux G., Martini M., Mossaz S., Podbevsek D., Qiu X., Tillement O. (2017) Hydrodynamic cavitation through "Labs on a Chip": from fundamentals to applications, Oil Gas Sci. Technol. - Rev. IFP Energies nouvelles 72, 19.

32 Fan Y., Liu Y., Li H., Foulds I.G. (2012) Printed wax masks for $254 \mathrm{~nm}$ deep-UV pattering of PMMA-based microfluidics, J. Micromech. Microeng. 22, 027001.

33 Mathur A., Roy S.S., Mclaughlin J.A. (2010) Transferring vertically aligned carbon nanotubes onto a polymeric substrate using a hot embossing technique for microfluidic applications, J. R. Soc. Interface 7, 1129-1133.

34 Liqun D.U., Chang H., Song M., Liu C. (2012) The effect of injection molding PMMA microfluidic chips thickness uniformity on the thermal bonding ratio of chips, Microsyst. Technol. 18, 815-822.

35 Hong T.F., Ju W.J., Wu M.C., Tai C.H., Tsai C.H., Fu L.M. (2010) Rapid prototyping of PMMA microfluidic chips utilizing a $\mathrm{CO}_{2}$ laser, Microfluid. Nanofluid. 9, 11251133.

36 Kar A., Chiang T.Y., Rivera I.O., Sen A., Velegol D. (2015) Enhanced transport into and out of dead-end pores, $A C S$ Nano. 9, 746-753. 